\title{
Red blood cell transfusion and skeletal muscle tissue oxygenation in anaemic haematologic outpatients
}

\author{
Matej Podbregar ${ }^{1,2}$, Ana Ursula Gavric², Eva Podbregar², Hugon Mozina³, \\ Sebastian Stefanovic ${ }^{2}$ \\ ${ }^{1}$ Clinical Department for Anaesthesiology and Surgical Intensive Care, University Medical Centre Ljubljana, Slovenia \\ 2 Faculty of Medicine, University of Ljubljana, Ljubljana, Slovenia \\ ${ }^{3}$ Emergency Department, University Medical Centre Ljubljana, Ljubljana, Slovenia
}

Radiol Oncol 2016; 50(4): 449-455.

Correspondence to: Prof. Matej Podbregar, M.D., Ph.D., Clinical Department for Anaesthesiology and Surgical Intensive Care, University Medical Centre Ljubljana, Ljubljana, Slovenia. Phone: +386 4021 5960; E-mail: matej.podbregar@guest.arnes.si

Disclosure: No potential conflicts of interest were disclosed.

Background. Stored red blood cells (RBCs) accumulate biochemical and biophysical changes, known as storage lesion. The aim of this study was to re-challenge current data that anaemia in chronically anaemic haematology patients is not associated with low skeletal muscle tissue oxygen $\left(\mathrm{StO}_{2}\right)$, and that RBC storage age does not influence the tissue response after ischaemic provocation, using near-infrared spectroscopy.

Patients and methods. Twenty-four chronic anaemic haematology patients were included. Thenar skeletal muscle $\mathrm{StO}_{2}$ was measured at rest (basal $\mathrm{StO}_{2}$ ), with vascular occlusion testing (upslope $\mathrm{StO}_{2}$, maximum $\mathrm{StO}_{2}$ ) before and after transfusion.

Results. Basal $\mathrm{StO}_{2}$ was low (53\% $\pm 7 \%$ ). Average RBC storage time was $10.5 \pm 3.9$ days. Effects of RBC transfusions were as follows: basal $\mathrm{StO}_{2}$ and upslope $\mathrm{StO}_{2}$ did not change significantly; maximum $\mathrm{StO}_{2}$ increased compared to baseline ( $64 \pm 14 \%$ vs. $59 \pm 10 \%, \mathrm{p}=0.049$ ). Change of basal $\mathrm{StO}_{2}$, upslope $\mathrm{StO}_{2}$ and maximum $\mathrm{StO}_{2}$ was negatively related to age of RBCs. The decrease of maximum $\mathrm{StO}_{2}$ was predicted (sensitivity $70 \%$, specificity $100 \%$ ), after receiving RBCs $\geq 10$ days old.

Discussion. Resting skeletal muscle $\mathrm{StO}_{2}$ in chronic anaemic patients is low. $\mathrm{RBC}$ storage time affects skeletal muscle $\mathrm{StO}_{2}$ in the resting period and after ischaemic provocation.

Key words: skeletal muscle; tissue oxygenation; red blood cells; transfusion; storage lesion

\section{Introduction}

Anaemia is state of decreased blood oxygen carrying capacity. ${ }^{1}$ Acute anaemia is associated with increased tissue oxygen extraction. ${ }^{2}$ On the other hand, with chronic anaemia human body has time to at least partially adapt to decreased blood oxygen carrying capacity.,

Near-infrared spectroscopy (NIRS) is non-invasive method to assess tissue oxygenation $\left(\mathrm{StO}_{2}\right)$ and estimate tissue haemoglobin ( $\mathrm{THb})$ levels. ${ }^{5} \mathrm{We}$ have studied skeletal muscle $\mathrm{StO}_{2}$ in critically ill patients with preserved oxygen (i.e., cardiogenic shock) and with impaired oxygen extraction (i.e., septic shock) ${ }^{6-9}$ In addition to measuring resting $\mathrm{StO}_{2}$, we performed vascular occlusion tests to stop arterial blood flow, to estimate oxygen consumption, and at the end of the occlusion, it was also possible to estimate vascular reactivity and maximal reperfusion capability. ${ }^{10}$

Under acute blood loss in trauma patients, the skeletal muscle $\mathrm{StO}_{2}$ measured by NIRS correlates with blood haemoglobin $(\mathrm{Hb})$ and delivery of oxygen, and can easily detect latent stage of haemorrhagic shock. ${ }^{11}$ Unexpectedly, chronically anaemic haematology patients with preserved oxygen ex- 


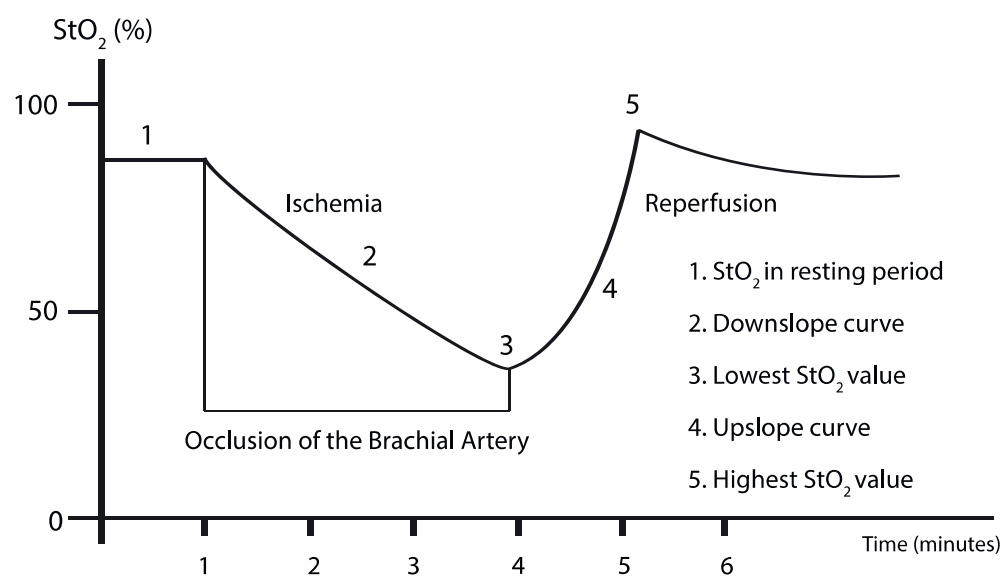

FIGURE 1. Schematic presentation of thenar skeletal muscle $\mathrm{StO}_{2}$ before, during and after the vascular occlusion tests. Before the vascular occlusion, the $\mathrm{StO}_{2}$ is measured in the resting period $\left(1\right.$, basal $\mathrm{StO}_{2}$ ). During the vascular occlusion, the $\mathrm{StO}_{2}$ gradually decreases. The rate of this decrease is determined from the curve as the downslope $\mathrm{StO}_{2}(2 ; \% / \mathrm{min})$, as a surrogate of the tissue oxygen consumption. After reaching the predetermined minimum $\mathrm{StO}_{2}$, present here as $40 \% \mathrm{StO}_{2}$ (3), the vascular occlusion is released, and the $\mathrm{StO}_{2}$ begins to rise again. The rate of this increase is determined from the curve as the upslope $\mathrm{StO}_{2}(4 ; \% / \mathrm{min})$, as a surrogate marker of the microcirculatory reactivity. After the release of the occlusion, the $\mathrm{StO}_{2}$ increases to higher values compared to the basal $\mathrm{StO}_{2}$ due to post-ischaemic vasodilatation $\left(5\right.$, maximum $\left.\mathrm{StO}_{2}\right)$. The $\mathrm{StO}_{2}$ then slowly returns to the basal $\mathrm{StO}_{2}$.

traction capability did not show low skeletal $\mathrm{StO}_{2}$ and $\mathrm{THb}$ index despite their severe anaemia, which is what would be predicted from normal physiological responses. ${ }^{12}$

It is known that there are structural and functional changes to RBCs during storage. Recent study detected deleterious effects of RBC storage on microvascular responses to transfusion in stable anaemic trauma patients. ${ }^{13}$

The aim of the present study was to re-challenge the current data that anaemia in chronically anaemic haematology patients is not associated with low skeletal muscle $\mathrm{StO}_{2}$, and that the age of RBCs does not influence tissue responses. We investigated these aspects using improved technology NIRS devices, for deeper tissue penetration and removal of the superficial signal from the skin.

\section{Materials and methods}

The study was approved by the National Medical Ethics Committee of the Republic of Slovenia $\left(\mathrm{N}^{\circ} 117 / 06 / 12,29.06 .2012\right)$. All of the patients were informed of the goals of the study, and signed their written consent. This study was carried out according to the Helsinki-Tokyo Declaration.

\section{Patients}

This prospective observational study included patients that were treated in the Outpatient Haematology Clinic of Clinical Department of Haematology, University Medical Centre Ljubljana. All of the patients included were in need of a blood transfusion, which was ordered by treating physicians who were not involved in the study. The exclusion criteria were age $<18$ years, and patient rejection of participation.

\section{Transfusions}

Leucodepleted RBC units in saline-adenine-glucose-mannitol additive solution and with maximal allowed haemolysis of $0.8 \%$ were acquired from the Blood Transfusion Centre of Slovenia. The patients were transfused with two units of RBCs with maximal age difference of 3 days.

\section{Near-infrared spectroscopy measurements and analysis}

The thenar skeletal muscle $\mathrm{StO}_{2}$ and $\mathrm{THb}$ concentrations were measured with tissue spectrometer (Equanox 7600; Nonin Medical, Minnesota,USA). The electrode (8004CA, Equanox Advance Sensor, Nonin Medical) was placed on the thenar eminence to measure the maximum resting $\mathrm{StO}_{2}$. During measurements, there were no additional treatment procedures in place, except for the RBC transfusion. All of the patients were positioned in a semirecumbent position.

In this resting period before the transfusion and after $\mathrm{StO}_{2}$ signal stabilisation, the basal $\mathrm{StO}_{2}(\%)$ and $\mathrm{THb}(\mathrm{g} / \mathrm{l})$ were determined. Then vascularocclusion test was performed, as reported previously. ${ }^{6}$ In short, a sphygmomanometer cuff was placed over the brachium, and the pressure cuff inflation was taken to $60 \mathrm{mmHg}$ over systolic blood pressure, to stop the blood flow in brachial artery. The $\mathrm{StO}_{2}$ decreased during this arterial occlusion, which was measured as the downslope $\mathrm{StO}_{2}(\% /$ $\mathrm{min}$ ). After reaching a $\mathrm{StO}_{2}$ of $40 \%$ (the minimum $\mathrm{StO}_{2}$ ) the cuff was released, and the $\mathrm{StO}_{2}$ and $\mathrm{THb}$ continuously measured for an additional $5 \mathrm{~min}$ (Figure 1). During this reperfusion, the $\mathrm{StO}_{2}$ increased rapidly, as the upslope $\mathrm{StO}_{2}(\% / \mathrm{min})$, and usually reached values higher than the basal $\mathrm{StO}_{2}$, to give the maximum $\mathrm{StO}_{2}(\%)$. The same procedure was carried out $30 \mathrm{~min}$ after the RBC transfusion.

These time-dependent $\mathrm{StO}_{2}$ values were continuously saved using the RealTerm software 
(http://realterm.sourceforge.net), which allowed a $1-\mathrm{Hz}$ sampling rate. The data acquired were further analysed off-line using the Microsoft Excel 2010 software (Microsoft, WA, USA).

All of the NIRS measurements were carried out without knowing the exact age of RBCs.

\section{Vital functions measurements}

Heart rate and systolic and diastolic blood pressures were measured (IntelliVueMP30, Philips Healthcare, Netherlands) before and after the transfusions, $5 \mathrm{~min}$ before NIRS measurements. Blood pressure was measured on the opposite hand to that used for NIRS measurements. Thenar skin temperature was measured immediately before NIRS measurements with a non-contact infrared clinical thermometer (Geratherm Medical AG Germany) (measuring range $34.0^{\circ} \mathrm{C}$ to $42.2^{\circ} \mathrm{C}$, accuracy of $\pm 0.2^{\circ} \mathrm{C}$ ).

\section{Laboratory measurements}

The $\mathrm{Hb}(\mathrm{g} / \mathrm{L})$ and haematocrit before the transfusions were acquired according to routine laboratory tests (CoulterLH750 Haematology Analyser, Beckman Coulter Inc, USA).

\section{Statistics}

The normal distribution of the data was tested using D'Agostino-Pearson tests. The data are given as means \pm standard deviation (SD), as medians and $95 \%$ confidence interval $(95 \% \mathrm{CI})$, or as absolute values (percentages based on the whole group or subgroup). Effects of transfusion on different variables were tested with paired samples T-test. Regression analysis was performed using Analysis of variance to test the effects of age of RBCs. ROC analysis and interactive dot diagram were used to find the age of RBCs, which predicted divergent response. MedCalc 13.0 software (MedCalc Software, Belgium) was used. $\mathrm{P}<0.05$ was considered as statistically significant.

\section{Results}

\section{Before the RBC transfusions}

Twenty-seven patients were initially included in the study. Two patients were excluded from further analysis due to technical difficulties while recording the NIRS, one because of received 3 units of RBCs. In remaining 24 patients, 11 (46\%) were female. The mean age of the patients was $65 \pm 12$
TABLE 1. Demographics, laboratory, haemodynamic and skeletal muscle NIRS variables of the patients before the RBC transfusions

\begin{tabular}{|c|c|}
\hline Characteristic & $\begin{array}{c}\text { All patients } \\
(n=28)\end{array}$ \\
\hline \multicolumn{2}{|l|}{ Demographics } \\
\hline Female [n (\%)] & $13(46)$ \\
\hline Age (years) & $65 \pm 12$ \\
\hline \multicolumn{2}{|l|}{ Laboratory data } \\
\hline Haemoglobin (g/L) & $77.9 \pm 12.4$ \\
\hline Haematocrit (\%) & $0.23 \pm 0.04$ \\
\hline \multicolumn{2}{|l|}{ Haemodynamics } \\
\hline Systolic blood pressure (mm Hg) & $122 \pm 19$ \\
\hline Diastolic blood pressure $(\mathrm{mm} \mathrm{Hg})$ & $68 \pm 10$ \\
\hline Heart rate (beats/min) & $78 \pm 17$ \\
\hline Thenar skin temperature $\left({ }^{\circ} \mathrm{C}\right)$ & $35.6 \pm 0.6$ \\
\hline \multicolumn{2}{|l|}{ NIRS in resting conditions } \\
\hline Basal $\mathrm{StO}_{2}, \%$ & $53 \pm 7$ \\
\hline Tissue haemoglobin ( $\mathrm{g} / \mathrm{L}$ ) & $1.13 \pm 0.14$ \\
\hline \multicolumn{2}{|l|}{ NIRS: during vascular occlusion test } \\
\hline Downslope $\mathrm{StO}_{2}(\% / \mathrm{min})$ & $-9.4 \pm 4.6$ \\
\hline Minimum $\mathrm{StO}_{2}(\%)$ & $39 \pm 5$ \\
\hline Upslope $\mathrm{StO}_{2}(\% / \mathrm{min})$ & $78 \pm 51$ \\
\hline Maximum $\mathrm{StO}_{2}(\%)$ & $59 \pm 10$ \\
\hline
\end{tabular}

Data are means \pm SD

years. Myelodysplastic syndrome was the cause of anaemia in $16(67 \%)$ patients, plasmacytoma in 4 $(17 \%)$, leukaemia in $3(12 \%)$, amyloidosis in 1 (4\%). The demographic data, laboratory values, haemodynamic variables and skeletal muscle NIRS data of the patients before transfusion are presented in Table 1 .

In all patients received 2 units of RBCs. The average storage time of the RBCs was $10.5 \pm 3.9$ days.

\section{After the RBC transfusions}

Compared to baseline $\mathrm{Hb}(77.9 \pm 12.4 \mathrm{~g} / \mathrm{L}$ vs. $94.4 \pm$ $17.4 \mathrm{~g} / \mathrm{L}, \mathrm{p}<0.01)$ and haematocrit $(0.23 \pm 0.04 \%$ vs $0.30 \pm 0.03 \%, p<0.01)$ increased after transfusion.

Systolic arterial pressure appeared not to be greatly affected by the RBC transfusions (122 \pm 19 $\mathrm{mm} \mathrm{Hg}$ vs. $124 \pm 21 \mathrm{~mm} \mathrm{Hg}, \mathrm{p}=0.5)$. Diastolic arterial pressure increased $(68 \pm 10 \mathrm{~mm} \mathrm{Hg}$ vs. $77 \pm 16$ $\mathrm{mm} \mathrm{Hg}, \mathrm{p}=0.013)$ and heart rate decreased after transfusion (78 $\pm 17 \mathrm{bpm}$ vs. $73 \pm 17 \mathrm{bpm}, \mathrm{p}=0.01)$ after transfusion. 
(A)

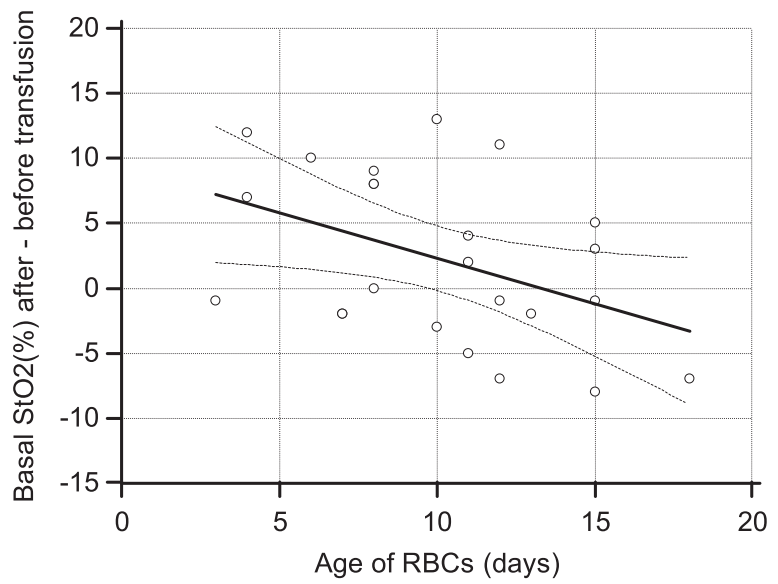

\begin{tabular}{llllll}
\hline$y=9,3124+-0,7016$ & $x$ & & & \\
\hline Parameter & Coefficient & Std. Error & $95 \% \mathrm{Cl}$ & $\dagger$ & $\mathrm{P}$ \\
Intercept & 9,3124 & 3,3712 & 2,3209 to 16,3039 & 2,7623 & 0,0114 \\
Slope & $-0,7016$ & 0,3111 & $-1,3467$ to $-0,05654$ & $-2,2556$ & 0,0344 \\
F-ratio & 5,0878 & & & & \\
Significance level & $\mathrm{P}=0,034$ & & & & \\
\hline
\end{tabular}

\section{(B)}

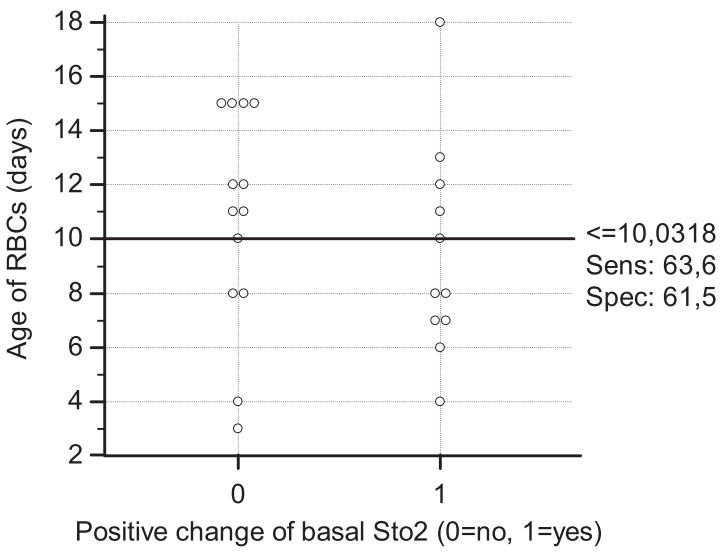

FIGURE 2. Effects of the age of the RBCs for the transfusions on the basal $\mathrm{StO}_{2}$. (A) Regression/analysis of variance. (B) ROC analysis, interactive dot diagram for optimal effect separation.

Prediction line (solid lines); 95\% confidence line (dashed lines)

The thenar skin temperature remained unchanged, while $\mathrm{THb}$ increased after transfusion $(1.13 \pm 0.14 \mathrm{~g} / \mathrm{L}$ vs. $1.22 \pm 0.17 \mathrm{~g} / \mathrm{L}, \mathrm{p}=0.006)$.

Basal $\mathrm{StO}_{2}$ under resting conditions before the vascular occlusion did not differ significantly before and after RBC transfusion $(53 \pm 7 \%$ vs. $55 \pm 7 \%$, $\mathrm{p}=0.10)$. As well there was no significant change of the downslope $\mathrm{StO}_{2}(-9.4 \pm 4.9 \% / \mathrm{min} v s .-10.3 \pm$ 8.4 min, $\mathrm{p}=0.29)$, the minimum $\mathrm{StO}_{2}(39 \pm 5 \%$ vs. $40 \pm 3 \%, \mathrm{p}=0.57)$ and the upslope $\mathrm{StO}_{2}(78 \pm 51 \% /$ $\min v s .82 \pm 59 / \mathrm{min}, \mathrm{p}=0.736)$. The maximum $\mathrm{StO}_{2}$ values increased after RBCs transfusion compared to pre-transfusion measurements $(64 \pm 14 \%$ vs. $59 \pm$ $10 \%, \mathrm{p}=0.049$ ).

The age of RBCs transfused influenced the skeletal muscle $\mathrm{StO}_{2}$ in resting conditions and during vascular occlusion testing. With increasing age the basal $\mathrm{StO}_{2}$ increased less (basal $\mathrm{StO}_{2}=9.3124$ $0.7016^{*}$ age of RBCs in days; slope C195\%: -1.3467 to $-0.0565, \mathrm{p}=0.0344$ ) (Figure $2 \mathrm{~A}$ ). While receiving $\mathrm{RBCs} \geq 10$ days old, the decrease of basal $\mathrm{StO}_{2}$ was predicted with sensitivity $63.6 \%$ and specificity $61.5 \%$ (Figure 2B). Upslope $\mathrm{StO}_{2}$ was also negatively related to the age of $\mathrm{RBCs}$ (upslope $\mathrm{StO}_{2}=$ $64.3744-5.9782$ * age of RBCs in days; slope CI95\% : -11.5759 to $-0.380, p=0.0374$ ); while receiving RBCs $\geq 10$ days old, the decrease of the upslope $\mathrm{StO}_{2}$ was predicted with sensitivity $63.6 \%$ and specificity $61.5 \%$ (Figures 3A, 3B). The change of maximum $\mathrm{StO}_{2}$ was negatively relate to $\mathrm{RBCs}$ age (Maximum $\mathrm{StO}_{2}=20.8870+-1.4950^{*}$ age of RBCs in days; slope C195\% : -2.7347 to $-0.2553, \mathrm{p}=0.0203$ ); while receiving $\mathrm{RBCs} \geq 10$ days old, the decrease of the maximum $\mathrm{StO}_{2}$ was predicted with sensitivity $70 \%$ and specificity $100 \%$. There was no relationship between change of $\mathrm{Hb}, \mathrm{THb}$ and downslope $\mathrm{StO}_{2}$ with age of RBCs.

\section{Discussion}

Our findings confirm the low resting thenar skeletal muscle $\mathrm{StO}_{2}$ in chronic anaemic haematology patients, and also the positive effects of RBCs on maximum $\mathrm{StO}_{2}$ after vascular occlusion test- after reperfusion. Age of RBCs was negatively related to change of basal, upslope and maximum $\mathrm{StO}_{2}$; age of RBCs $\geq 10$ days was found to predict divergent response of skeletal muscle $\mathrm{StO}_{2}$ different responses of skeletal muscle $\mathrm{StO}_{2}$.

In these patients, the resting $\mathrm{StO}_{2}(53 \% \pm 7 \%)$ was lower than that expected for normal healthy volunteers $(83 \% \pm 4 \%){ }^{6}$ Studies that have including patients with acute anaemia have also reported low skeletal muscle $\mathrm{StO}_{2}$. On the other hand, surprisingly, Yurku et al. did not detect such expected low $\mathrm{StO}_{2}$ of thenar eminence in anaemic haematology outpatients ${ }^{12}$, although their RBC transfusions were successful in improving these variables. The explanation for these contradictory data probably lies with the NIRS probe they used (length $15 \mathrm{~mm}$; penetration, ca.7 mm). Their kind of probe mainly detects changes in skin and subdermal tissue, which is, however, not the main issue in clinical use of NIRS. ${ }^{14}$ The thenar skin and subdermal tissue are $3-4 \mathrm{~mm}$ thick, and these layers are even 
thicker for oedematous patients. By using probes with deeper penetration or devices that can filter out superficial layers and bones, the organ/skeletal muscle $\mathrm{StO}_{2}$ can be better monitored, which is also more interesting for daily clinical practice (i.e., the device used in the present study). The importance of the probe and site has been shown previously. ${ }^{15,16}$ Superficial structures are more prone to changes in peripheral circulation and ambient temperature. ${ }^{17}$

Our data that show here that skeletal muscle $\mathrm{StO}_{2}$ in the resting period is influenced by age of the RBCs is supported by Leal-Noval et al., who showed increases in cerebral oxygenation in patients with severe traumatic brain injury if the RBCs were stored for $<19$ days. Their data suggested an inverse association between increments in brain oxygen tension and RBC storage time. ${ }^{18}$

Kiraly et al. using $25 \mathrm{~mm}$ NIRS showed probe, that transfusion of older RBCs ( $>21$ days) resulted in decreased skeletal muscle $\mathrm{StO}_{2}$ in critically injured trauma patients. They reported a moderate correlation between increasing age of blood and decrease of oxygenation. ${ }^{19}$

Recent study also confirmed the deleterious effects of RBC storage on microvascular responses to transfusion in trauma patients. ${ }^{13}$ The transfusion of relatively older RBC units was associated with a decline in both $\mathrm{StO}_{2}$ and perfused capillary vascular density. They even predicted a mean decrease in $\mathrm{StO}_{2}$ during the duration of the transfusion that was related to the RBC age $(-0.1064 \times$ age of transfusion in days).

Other studies carried out in septic patients did not confirm the present data that the age of the blood has an impact on the tissue saturation measured in the resting period. ${ }^{20,21}$ Patients in sepsis/ septic shock have imbalanced autoregulation of the blood flow in their peripheral tissues. ${ }^{10}$ Volume resuscitated anaemic septic patients already have relatively high resting skeletal muscle $\mathrm{StO}_{2}$. Roberson et al. did not find any differences in $\mathrm{StO}_{2}$ of the brain and of the thenar muscle of healthy volunteers after transfusion of one unit of RBCs that was either 7 or 42 days old. ${ }^{22}$

In the present study, the divergent responses of resting thenar skeletal muscle $\mathrm{StO}_{2}$ after receiving old blood could not be simply explained by an elevation of their blood $\mathrm{Hb}$ content only in the patients treated with fresh blood, which will lead to the increases in the oxygen delivery to the tissue, because there was no relationship between $\mathrm{Hb}$ or $\mathrm{THb}$ and age of RBCs. There is another explanation possible. In most tissues ratio of the arteriole to capillary to venous compartments is approximate-
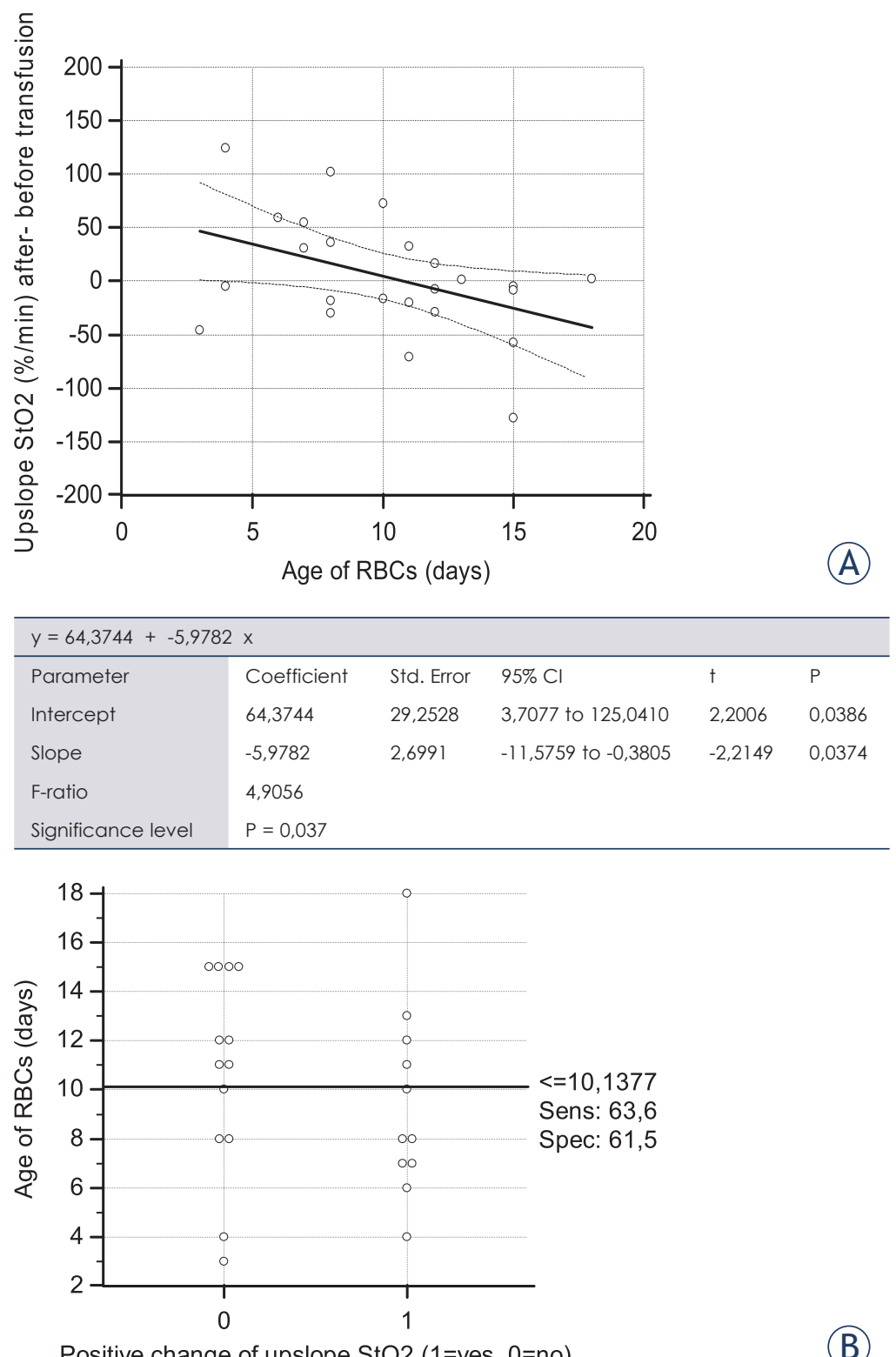

FIGURE 3. Effects of the age of the RBCs for the transfusions on the upslope $\mathrm{StO}_{2}$. (A) Regression/analysis of variance. (B) ROC analysis, interactive dot diagram for optimal effect separation.

Prediction line (solid lines); 95\% confidence line (dashed lines

ly 10:20:70. ${ }^{23}$ In case of a ratio change due to benefits for the arterial or capillary parts in comparison to the venous part, we might expect an elevation of $\mathrm{StO}_{2}$ in the resting period, without considering the equal increases in $\mathrm{THb}$ concentrations. The differences between these vascular compartments might be changed to the benefit of the arterial and capillary systems in the patients treated with fresh blood because of less disturbance of nitric oxide (NO) metabolism in these fresher RBCs, with fewer 


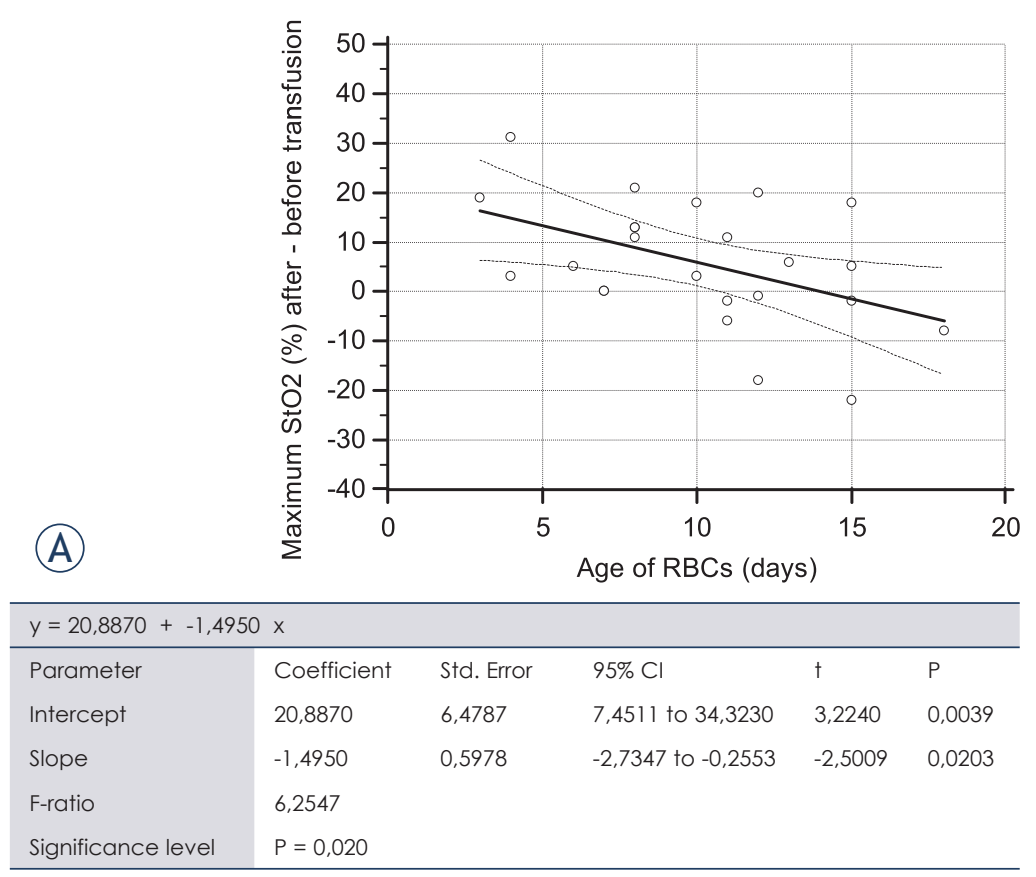

(B)

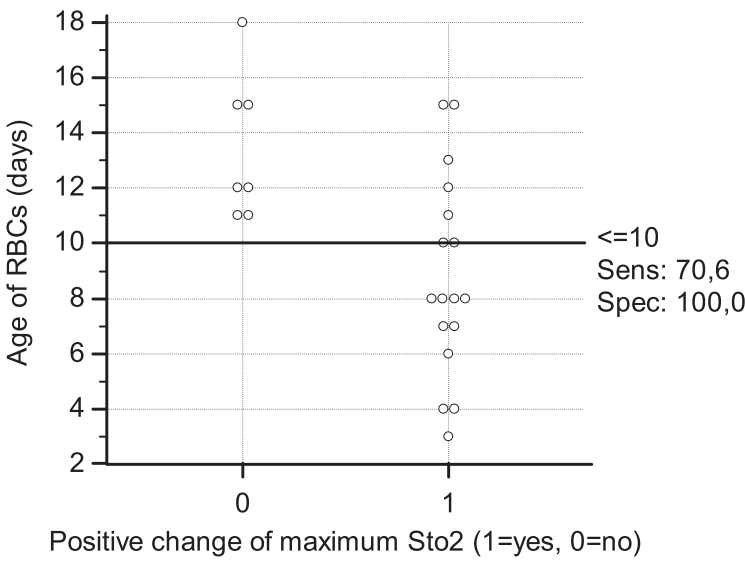

FIGURE 4. Effects of the age of the RBCs for the transfusions on the maximum $\mathrm{StO}_{2}$. (A) Regression/analysis of variance. (B) ROC analysis, interactive dot diagram for optimal effect separation

Prediction line (solid lines); 95\% confidence line (dashed lines)

degraded $\mathrm{RBC}$ products and a lower free $\mathrm{Hb}$ content, which are all NO-scavenging substances. ${ }^{24}$

It was shown that NO metabolism becomes disturbed in blood with storage duration $>14$ days. ${ }^{24}$ Using competition kinetics analysis, it was also recently demonstrated that compared with freshly prepared RBCs, the consumption rates of NO increase approximately 40 -fold and NO-dependant vasodilatation is inhibited 2-4-fold in 42-day-old RBCs. ${ }^{13}$

This decreased vascular reactivity (upslope and maximum $\mathrm{StO}_{2}$ ) found in patients treated with older blood can also be explained in terms of more disturbance of $\mathrm{NO}$ metabolism in older blood. ${ }^{24}$ NO has an important effect on vascular homeostasis, which is known as NO-based vasodilatation. ${ }^{24}$ Post-ischaemic hyperaemia, which develops with vascular occlusion, is one of the most important and reproducible indicators of microcirculatory responses. ${ }^{25}$

Bennett-Guerrero et al. studied effects of storage on the deformability of RBCs, on RBCdependent vasoregulation, and on the changes in S-nitrosohaemoglobin $(\mathrm{SNO}-\mathrm{Hb})$ concentrations. ${ }^{26}$ They observed significant drop in SNO-Hb concentrations in RBCs only $3 \mathrm{~h}$ after blood donation, which might have been a reason for decreased vasodilatation after RBC transfusions. Reynolds et al. determined that there is possible regeneration of $\mathrm{SNO}-\mathrm{Hb}$ in the received RBCs in vivo, which enables RBC-dependent vasodilatation and optimisation of blood perfusion through the peripheral tissues. ${ }^{27}$

The present study poses some new questions. Further studies should focus on the effects of NO scavenging in RBCs that are stored for longer; also, whether aged RBCs can also be used as a therapeutic option, such as for septic patients, who have excessively induced NO synthesis.

\section{Conclusions}

The resting skeletal muscle $\mathrm{StO}_{2}$ in chronically anaemic haematology patients is low. The RBC storage time affects the skeletal muscle tissue oxygenation of these patients.

\section{Acknowledgements}

We thank the nurses in the Haematology OutPatient Clinic for their help and patience during this study, Prof. Črnelč P, Head of the Haematology Department, for his cooperation.

This study was supported by the Tertiary Research Programme of the University Medical Centre Ljubljana and the P3-0043 Research Programme of the Slovenian Research Agency.

\section{Authors' contributions}

MP contributed to the conception and design of the study, acquisition, analysis and interpretation of the data, statistical analysis, drafting and critically reviewing the manuscript for important intellec- 
tual content, and submitting the manuscript; AUG, $\mathrm{EP}$, and SS contributed to the conception and design of the study, acquisition of data, drafting the manuscript, and critical revision of the manuscript for important intellectual content; HM contributed to the conception and design of the study, statistical analysis, and critical revision of the manuscript for important intellectual content.

\section{References}

1. Adamson WJ, Longo LD. Anemia and polycythemia. In: Longo LD, Fauci SA, Kasper LD, et al. Harrison's principles of internal medicine. 18th edition. New York: McGrawHill Medical; 2012. p. 448-57.

2. Roberson SR, Bennett-Guerreo E. Impact of red blood cell transfusion on global and regional measures of oxygenation. Mt Sinai J Med 2012; 79: 66-74.

3. Madjdpour C, Spahn DR. Allogeneic red blood cell transfusions: efficacy, risks, alternatives and indications. Br J Anaesth 2005; 95: 33-42.

4. Klein HG, Spahn DR, Carson JL. Red blood cell transfusion in clinical practice. Lancet 2007; 370: 415-26.

5. Ferrari M, Giannini I, Sideri G, Zanette E.Continuous non invasive monitoring of human brain by near infrared spectroscopy. Adv Exp Med Biol 1985; 191: 873-82.

6. Pareznik R, Knezevic R, Voga G, Podbregar M. Changes in muscle tissue oxygenation during stagnant ischemia in septic patients. Intensive Care Med 2006; 32: 87-92.

7. Možina H, Podbregar M. Near infrared spectroscopy for evaluation of skeletal muscle tissue oxygenation in different types of shock. Signa Vitae 2015; 10: 10-24.

8. Možina H, Podbegar M. Near-infrared spectroscopy for evaluation of global and skeletal muscle tissue oxygenation. World J Cardiol 2011; 3: 377-82.

9. Crookes BA, Cohn SM, Burton EA, Nelson J, Proctor KG. Noninvasive muscle oxygenation to guide fluid resuscitation after traumatic shock. Surgery 2004; 135: 662-70.

10. Yuruk K, Bartels SA, Milstein DM, Bezemer R, Biemond BJ, Ince C. Red blood cell transfusions and tissue oxygenation in anemic hematology outpatients. Transfusion 2012; 52: 641-6.

11. Weinberg JA, MacLennan PA, Vandromme-Cusick MJ, Magnotti $\sqcup$, Kerby JD, Rue LW 3rd, et al. The deleterious effect of red blood cell storage on microvascular response to transfusion. I Trauma Acute Care Surg 2013; 75: 807-12.

12. Podbregar $M$. Thenar tissue oxygen saturation monitoring: noninvasive does not mean simple or accurate! Crit Care Med 2012; 40: 712-3.

13. Bezemer R, Lima A, Myers D, Klijn E, Heger M, Goedhart PT, et al. Assessment of tissue oxygen saturation during a vascular occlusion test using near-infrared spectroscopy: the role of probe spacing and measurement site studied in healthy volunteers. Crit Care 2009; 13 (Suppl 5): S4.

14. Gómez H, Mesquida J, Simon P, Kim HK, Puyana JC, Ince C, et al. Characterization of tissue oxygen saturation and the vascular occlusion test:influence of measurement sites, probe sizes and deflation thresholds. Crit Care 2009; 13 (Suppl 5): S3.

15. Lima A, van Bommel J, Sikorska K, van Genderen M, Klijn E, Lesaffre E, et al. The relation of near-infrared spectroscopy with changes in peripheral circulation in critically ill patients. Crit Care Med 2011; 39: 1649- 54.

16. Leal-Noval SR, Muñoz-Gómez M, Arellano-Orden V, Marín-Caballos A, Amaya-Villar R, Marín A, et al. Impact of age of transfused blood on cerebral oxygenation in male patients with severe traumatic brain injury. Crit Care Med 2008; 36: 1290-6.

17. Kiraly LN, Underwood S, Differding JA, Schreiber MA. Transfusion of aged packed red blood cells Results in decreased tissue oxygenation in critically injured trauma patients. J Trauma 2009; 67: 29-32.
18. Sakr Y, Chierego M, Piagnerelli M, Verdant C, Dubois MJ, Koch M, et al. Microvascular response to red blood cell transfusion in patients with severe sepsis. Crit Care Med 2007; 35: 1639-44.

19. Creteur J, Neves AP, Vincent JL. Near-infrared spectroscopy technique to evaluate the effects of red blood cell transfusion on tissue oxygenation. Crit Care 2009; 13 (Suppl 5): S11.

20. Roberson SR, Lockhart E, Shapiro NI. Impact of transfusion of autologous 7- versus 42-day-old AS-3 red blood cells on tissue oxygenation and the microcirculation in healthy volunteers. Transfusion 2012; 52: 2459-64.

21. Berra L, Coppadoro A, Yu B, Spagnolli E, Steinbicker AU, Bloch KD, et al. Transfusion of stored autologous blood does not alter reactive hyperaemia index in healthy volunteers. Anaesthesiology 2012; 117: 56-63.

22. Stapley R, Owusu BY, Brandon A, Cusick M, Rodriguez C, Marques MB, et al. Erythrocyte storage increases rates of NO- and Nitrite scavenging: Implications for transfusion related toxicity. Biochem J 2012; 446: 499-508.

23. Vallet B. Vascular reactivity and tissue oxygenation. Intens Care Med 1988; 24: 3-11.

24. Bennett-Guerrero E, Veldman TH, Doctor A, Telen MJ, Ortel TL, Reid TS, et al. Evolution of adverse changes in stored RBCs. Proc Natl Acad Sci U S A 2007; 104: 17063-8.

25. Reynolds JD, Ahearn GS, Angelo M, Zhang J, Cobb F, Stamler JS S-nitrosohemoglobin deficiency: A mechanism for loss of physiological activity in banked blood. Proc Natl Acad Sci USA 2007; 104: 17058-62. 